\title{
A note \\ on new velocity distribution for wide rivers
}

\author{
by D. Chandrasekaran and Dr. R. Sakthivadivel \\ Hydraulic and Water Resources Department \\ College of Engineering \\ Madras (India)
}

Introduction

The theory of turbulent flow was first proposed by Osborne Reynolds and was subsequently developed by Prandtl and Von Karman, introducing certain simplified assumptions. Prandtl assumed not only a linear relationship between the mixing length and the wall distance in the boundary layer but also extended it up to the centre line of the pipe which appears to be somewhat an unreasonable as sumption. Von Karman made the assumption that the mixing length is a function of the velocity distribution only. This as sumption leads to the singularity that the derivative of the velocity with respect to the wall distance does not vanish at the centre line where the velocity is maximum, as in the case of Prandtl's theory.

A. Zagustin and K. Zagustin [1] have recently given an analytical solution for turbulent flow in pipes, which is free from the above mentioned assumptions. Their solution is based on a new concept of "balance of pulsation energy". This solution, when compared with some experimental results in pipes, fits better than Prandtl's and Von Karman's equations [1]. However, this solution has not been applied to problems in open channels where the flow situation is somewhat different from that in pipes. In this note, the velocity distribution formula for wide rivers obtained by this new concept is verified with field data. An expression for determining the Manning's roughness coefficient ' $n$ ' is derived using this new velocity distribution and compared with the existing expressions and the values of ' $n$ ' computed from field data.

\section{Verification of the velocity distribution}

A. Zagustin and K. Zagustin [1] had derived the formula for velocity distribution in pipe flow as

$$
\frac{U-u}{v^{*}}=\frac{2}{k} \tanh ^{-1}\left(\frac{r}{r_{0}}\right)^{3 / 2}
$$

where $U$ is the maximum velocity at the centre line of the pipe, $u$ the velocity at a distance $r$ from the centre line, $v^{*}$ is the usual friction velocity and $k$ is a universal constant. The maximum velocity $U$ may be eliminated from equation (1) using the condition that at a distance $y_{0}$ from the bed, the velocity is zero. It is usual to assume $y_{0}=h / 30$ where $h$ is the roughness height in feet [2]. Using this condition, the velocity distribution formula given by equation (1) is rewritten for open channel flow as:

$$
u=\frac{2 v^{*}}{k}\left\{\tanh ^{-1}\left(\frac{30 H-h}{30 H}\right)^{3 / 2}-\tanh ^{-1}\left(\frac{H-y}{H}\right)^{3 / 2}\right\}
$$

where $H$ is the depth of flow and $y$ is the distance measured from the bed of the channel.

To verify equation (2), some typical data from the ones reported in the Geological Survey Professional Paper 462-B [3] for the reaches of the Rio Grande near Bernallilo, Socorrow and Bernardo are chosen. For a given depth of flow at a given section the first term on the right side of equation (2) is a constant and hence, equation (2) will 
plot as a straight line between $u$ and $\tanh ^{-1}\left(\frac{H-y}{H}\right)^{3 / 2}$

The field data plotted in Fig. I verifies the new velocity distribution. From the intercepts and the slopes of the lines, it is possible to find the values of $k, h$ and $v^{*}$. It may be noted from the figure that for higher values of $y / H$, the deviations of the observed points from the theoretical line are pronounced as seen for Bernallilo reach; this may be attributed to the following reasons: All the velocity distribution equations for open channel flow were derived under the assumption that they follow the same law of distribution as in pipe flow in one half of its depth. According to this assumption, the maximum velocity for open channel flow should occur at the free surface, which corresponds to the centre line of the pipe. However, in practice, the position of the maximum velocity is lowered from the free surface due to cross currents. Hence, a discrepancy between the actual observed velocity and its theoretical value occurs in the neighbourhood of the free surface. This kind of discrepancy occurs also for the proposed velocity distribution equation.

\section{Determination of Manning's ' $n$ '}

To use the Manning's formula for finding the mean velocity of flow, the predetermined value of ' $n$ ' is necessary. The value of ' $n$ ' can be estimated from the velocity distribution as follows. Previously Langbein [4], Boyer [5] and $V e n$ Te Chow [2] have analytically determined the value of

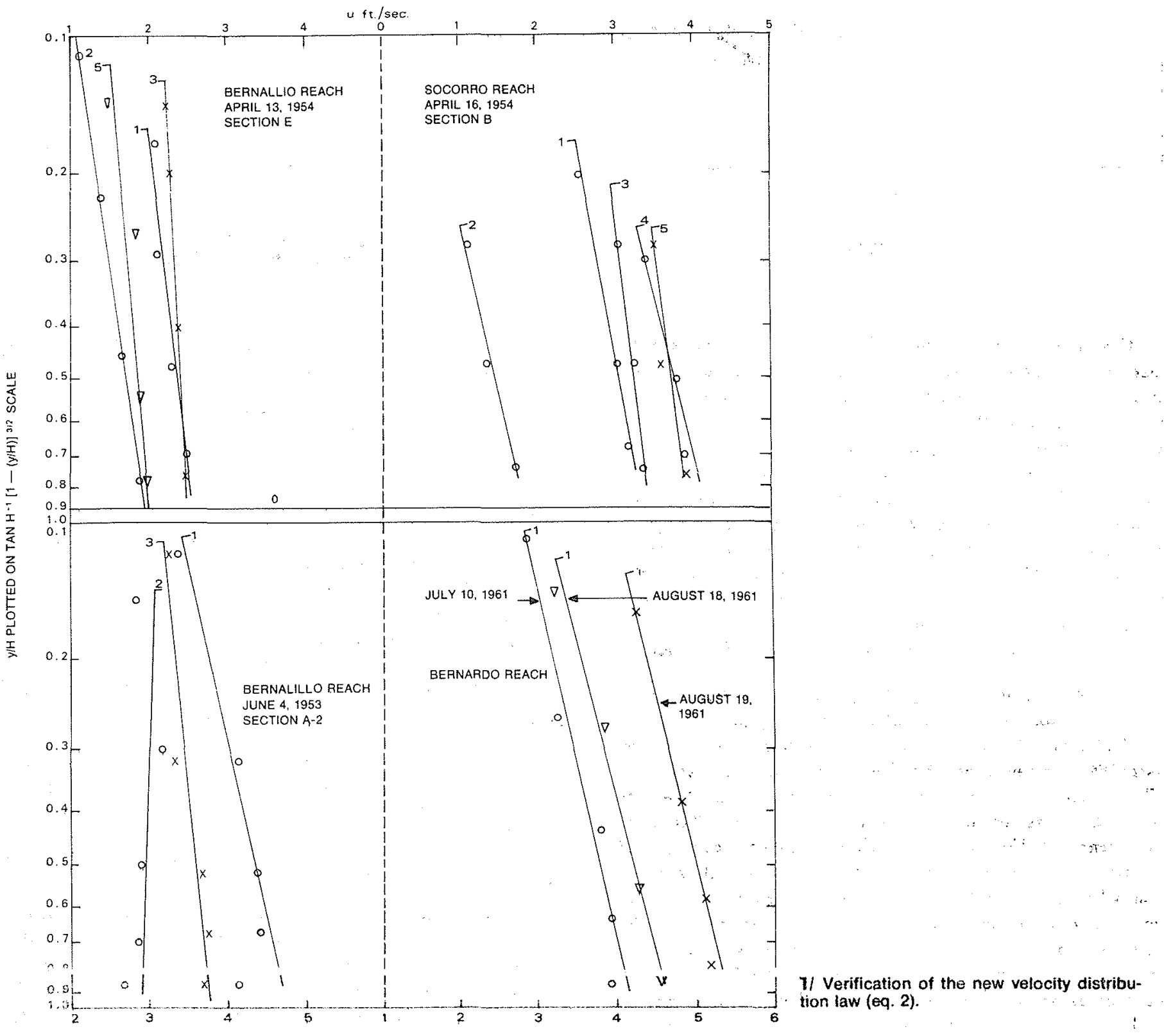


int based on Prandtl's and Von Karman's laws of velocity distribution [6]. The same procedure will be used in this case also. Assuming the mean velocity $V$ to be the average of the velocities at heights of $y=0.8 \mathrm{H}$ and $y=0.2 \mathrm{H}$ which gives a fairly correct value [7] and using equation (2), we get

$V=\frac{v^{*}}{2 k}\left\{2 \tanh ^{-1}\left(\frac{30 \mathrm{H}-\mathrm{h}}{30 \mathrm{H}}\right)^{3 / 2}-\tanh ^{-1}(0.8)^{3 / 2}-\tanh ^{-1}(0.2)^{3 / 2}\right\}$

From the Chezy's formula, $V=c \sqrt{R S}$ and from the definition of the friction velocity, $v^{*}=\sqrt{\mathrm{gRS}}$, one gets

$$
\mathrm{V} / \mathrm{v}^{*}=\mathrm{C} / \sqrt{\mathrm{g}}
$$

where $C$ is the Chezy's constant, $R$ is the hydraulic radius of the section, $S$ is the friction slope and $g$ is the acceleration due to gravity. Comparing Manning's formula

$$
V=\frac{1.486}{n} R^{2 / 3} S^{1 / 2}
$$

and the Chezy's formula, the value of $C$ is obtained in terms of $n$, and taking $R \approx H$ for a wide channel, equation (4) can be rewritten as

$$
\frac{V}{v^{*}}=\frac{1.486}{n \sqrt{g}} H^{1 / 6}
$$

Combining equations (3) and (5) leads to

$$
\begin{aligned}
\frac{1.486 H^{1 / 6}}{n \sqrt{9}} & =\frac{1}{2 k}\left\{2 \tanh ^{-1}\left(\frac{30 H-h}{30 H}\right)^{3 / 2}-\tanh ^{-1}(0.8)^{3 / 2}\right. \\
& \left.-\tanh ^{-1}(0.2)^{3 / 2}\right\}
\end{aligned}
$$

Denoting the ratio $\frac{{ }^{u} 0.8}{{ }_{0.2}}$ by $x$ where $v_{0.8}$ is the velocity at $y=0.8 \mathrm{H}$ and $u_{0.2}$, the velocity at $y=0.2 \mathrm{H}$, equation (2) is rewritten as

$$
x=\frac{\tanh ^{-1}\left(\frac{30 \mathrm{H}-h}{30 \mathrm{H}}\right)^{3 / 2}-\tanh ^{-1}(0.2)^{3 / 2}}{\tanh ^{-1}\left(\frac{30 \mathrm{H}-\mathrm{h}}{30 \mathrm{H}}\right)^{3 / 2}-\tanh ^{-1}(0.8)^{3 / 2}}
$$

Eliminating $\tanh ^{-1}\left(\frac{30 \mathrm{H}-\mathrm{h}}{30 \mathrm{H}}\right)^{3 / 2}$ from equations (6) and (7), the value of $n$ is obtained as

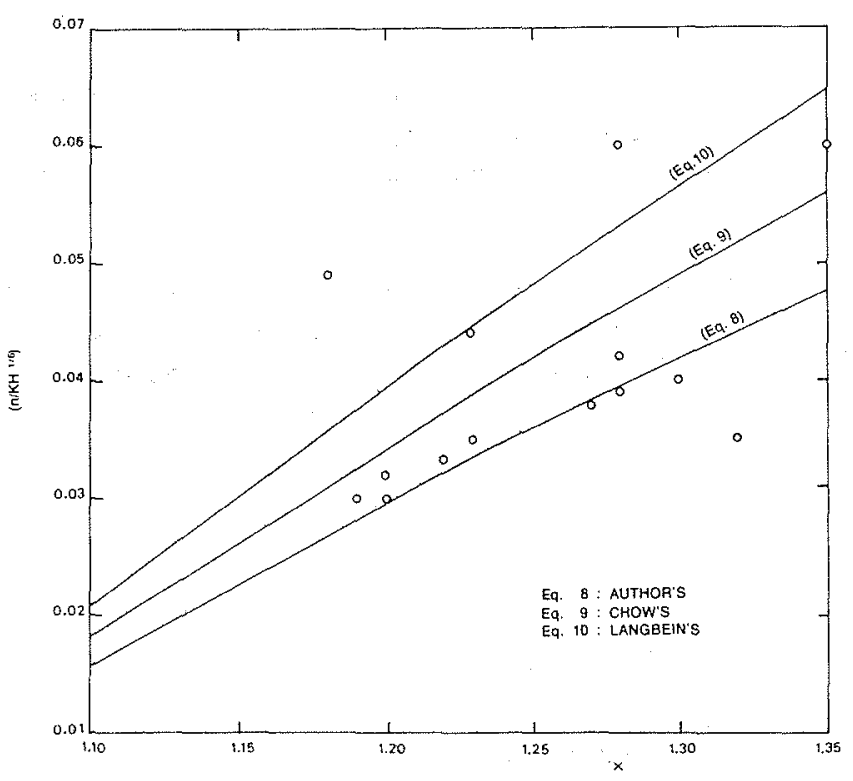

2/ Comparison of the values of Manning's ' $n$ '.

$$
\frac{n}{K H^{1 / 6}}=\frac{x-1}{3.09(x+1)}
$$

The corresponding expressions for $n$ which are obtained from Ven Te Chow's result [2] based on Prandtl's velocity distribution and from Langbein's result [4] based on Von Karman's velocity distribution are given in equations (9) and (10) respectively, as

$$
\begin{aligned}
& \frac{n}{K H^{1 / 6}}=\frac{x-1}{2.71(x+0.95)} \\
& \frac{n}{K H^{1 / 6}}=\frac{x-1}{2.30(x+1)}
\end{aligned}
$$

The curves of equations (8), (9) and (10) are plotted together with the points computed from the field data reported in references $[3,5]$. The points are based on the average value of $x$ computed from the velocity profiles taken at a section. $K$ is assumed to be 0.4 and $n$ was computed from the Manning's formula. It may be seen from Fig. 2 that equation (8) based on the new velocity distribution fits better than the other two equations based on the conventional laws of velocity distribution. It may be mentioned that. a narrow range of values of $x$ has been considered in Fig. 2 to be in compliance with the values which are actually obtained in practice. It may be further stated that the Boyer's equation [5] for the value of $n$ based on Prandtl's velocity distribution law plots practically over the curve given by equation (9) and as such, it is not shown in Fig. 2. 


\section{Conclusions}

1. The new velocity distribution law for pipes proposed by A. Zagustin and K. Zagustin based on the concept of "balance of pulsation energy" holds good even for flows in wide rivers.

2. The new velocity distribution yields a better value for the Manning's roughness coefficient $n$ than the Prandtl's and Von Karman's laws of velocity distributions.

\section{Notations}

C Chezy's Constant

g Acceleration due to gravity

$\mathrm{H} \quad$ Depth of flow

$h \quad$ Height of roughness

K Universal constant

$n \quad$ Manning's roughness coefficient

$\mathrm{R} \quad$ Hydraulic radius

$r \quad$ Distance from the axis of the pipe

$r_{0} \quad$ Radius of the pipe

$S \quad$ Friction slope

U Maximum Velocity at the pipe axis

$\checkmark \quad$ Velocity at any distance

$\checkmark \quad$ Mean velocity of flow

$v^{*} \quad$ Friction velocity

$x \quad$ Dimensionless ratio

y Variable distance
[1] ZAGUSTIN (A) and ZAGUSTIN (K).-Analytical solution for turbulent flow in pipes, La Houille Blanche, $n^{\circ} 2$ (1969), p. 113-118.

[2] VEN TE CHOW. - Open Channel Hydraulics, Mc. GrawHill Book Company, Inc., New York (1959), p. 200-209.

[3] NODIN (C.F.) and DEMESTER. (G.R.) - Vertical distribution of velocity and suspended sediment, Middle Rio Grande, New Mexico, Geological Survey Professional Paper 462-B (1963), p. B1-B20.

[4] LANGBEIN (W.E.). - Determination of Manning's $n$ from vertical velocity curve, Transactions American Geophysical Union, (July 1940), p. 618-620.

[5] BOYER (M.C.). - Estimating the Manning coefficient from an average bed roughness in open channels, Transactions American Geophysical Union, Vol. 35, $n^{\circ} 6$ (December 1954), p. 957-961.

[6] SCHLICHTING (H.). - Boundary layer theory. Mc. Graw Hill Book Company, Inc., New York (1960), p. 487-490.

[7] APMANN (R.P.M.). - Validity of two point method of velocity sampling, Journal of the Hydraulics Division, ASCE, Vol. 96 (October 1970), p. 2171-2176. 